Research Paper: Autophagy and Cell Death

\title{
Lithium protects hippocampal progenitors, cognitive performance and hypothalamus-pituitary function after irradiation to the juvenile rat brain
}

\author{
Kai Zhou ${ }^{1,2}$, Cuicui Xie ${ }^{1,3}$, Malin Wickström², Amalia M. Dolga4,5, Yaodong Zhang ${ }^{1,6}$,

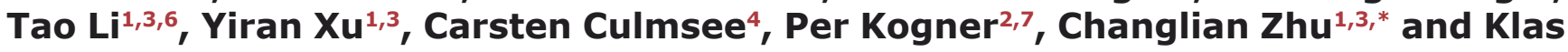 \\ Blomgren ${ }^{2,7, *}$ \\ ${ }^{1}$ Centre for Brain Repair and Rehabilitation, Institute of Neuroscience and Physiology, University of Gothenburg, Gothenburg, \\ Sweden \\ ${ }^{2}$ Karolinska Institutet, Department of Women's and Children's Health, Stockholm, Sweden \\ ${ }^{3}$ Henan Key Laboratory of Child Brain Injury, The Third Affiliated Hospital of Zhengzhou University, Zhengzhou, China \\ ${ }^{4}$ Institute of Pharmacology and Clinical Pharmacy, University of Marburg, Marburg, Germany \\ ${ }^{5}$ Department of Molecular Pharmacology, University of Groningen, Groningen Research Institute of Pharmacy, Groningen, \\ The Netherlands \\ ${ }^{6}$ Department of Paediatrics, Zhengzhou Children's Hospital, Zhengzhou, China \\ 7 Department of Paediatric Oncology, Karolinska University Hospital, Stockholm, Sweden \\ * These authors have equally contributed to this work \\ Correspondence to: Klas Blomgren, email: klas.blomgren@ki.se \\ Changlian Zhu, email: changlian.zhu@neuro.gu.se
}

Keywords: brain tumour; cell death; late effects; neuroinflammation; radiotherapy

Received: September 07, 2016 Accepted:March 01,2017 Published: March 16, 2017

Copyright: Zhou et al. This is an open-access article distributed under the terms of the Creative Commons Attribution License (CC-BY), which permits unrestricted use, distribution, and reproduction in any medium, provided the original author and source are credited.

\section{ABSTRACT}

Cranial radiotherapy in children typically causes delayed and progressive cognitive dysfunction and there is no effective preventive strategy for radiation-induced cognitive impairments. Here we show that lithium treatment reduced irradiationinduced progenitor cell death in the subgranular zone of the hippocampus, and subsequently ameliorated irradiation-reduced neurogenesis and astrogenesis in the juvenile rat brain. Irradiation-induced memory impairment, motor hyperactivity and anxiety-like behaviour were normalized by lithium treatment. Late-onset irradiationinduced hypopituitarism was prevented by lithium treatment. Additionally, lithium appeared relatively toxic to multiple cultured tumour cell lines, and did not improve viability of radiated DAOY cells in vitro. In summary, our findings demonstrate that lithium can be safely administered to prevent both short- and long-term injury to the juvenile brain caused by ionizing radiation.

\section{INTRODUCTION}

Brain tumours are the most frequent paediatric solid tumours and they represent the leading cause of mortality and morbidity by cancer in this age group [1]. Current treatment protocols for malignant paediatric brain tumours, the most common of which is medulloblastoma, typically include surgery, irradiation, and chemotherapy, a lifesaving combination that unfortunately contributes to long-term physical, endocrine, and neuropsychological impairments in survivors [2]. Radiotherapy often causes delayed and progressive cognitive impairments, such as deficits in memory, attention, and executive function $[3,4]$ with tremendous impact on the patients' quality of life. Cognitive function is one of the most important measurements of brain tumour therapy outcomes in clinical trials, second only to survival [5]. Clinical studies suggest that radiation-induced damage to the hippocampus plays a significant role in cognitive deficits [6-8]. Animal studies have shown that irradiation reduces hippocampal neurogenesis, and the mechanisms involved include 
apoptosis, neuroinflammation, and oxidative stress [911]. In addition, systemic effects of cranial irradiation, especially radiation-induced endocrinopathies, influence mental and physical development [12].

Efforts have been made to prevent or ameliorate the side effects induced by cerebral irradiation, for example by targeting different signalling pathways $[13,14]$. Clinical trials using memantine, a competitive N-methyl-D-aspartate (NMDA) receptor antagonist, exerted radioprotective effects in adult patients [15, 16], but as of yet there are no successful long-term treatments or effective preventive strategies safely used for radiation-induced cognitive impairments in children or adolescents $[17,18]$. The only strategy that has been tested in a clinical setting is physical exercise. Exercise is known to partly restore hippocampal neurogenesis and behaviour even when initiated long after irradiation in mice [11], and three very recent studies indicate that this may be effective also in children and young adults [19-21]. Regarding pharmacological strategies, lithium, when compared with memantine [22] or CNS stimulants, appears to exert multiple effects that reduce the negative effects of ionizing radiation. Several studies have indicated that lithium has robust neuroprotective effects in cranial irradiation paradigms [9, 23-25]. The protective properties include inhibition of stem or progenitor cell death and neuroinflammation [26], rescue of synaptic plasticity [27], and stimulation of stem and progenitor cell proliferation and neurogenesis $[9,28]$. Importantly, lithium does not appear to protect cancer cells [23] and may in some cases act as a radiosensitizer [29]. Before moving to clinical trials of lithium for prevention of radiationinduced cognitive impairments, it is important to assess its long-term effects on irradiation-induced brain injury, as well as systemic effects, mechanisms of action, and potential toxicity. Neurogenesis in the dentate gyrus of the hippocampus is important in long term memory formation, and it has been shown that ionizing radiation effectively impairs neurogenesis $[9,11]$. We have earlier found that lithium treatment effectively reduces ischemic as well as irradiation injury $[9,26,28,30,31]$. The purpose of this study was to test our hypothesis that lithium treatment could ameliorate irradiation-induced so called late effects, such as cognitive decline and endocrine dysfunction, by preventing cell death and promoting regeneration.

\section{RESULTS}

\section{Tumour cells are sensitive to lithium toxicity}

To examine the sensitivity difference of human tumour cells to lithium treatment, 7 brain tumour cell lines were treated with lithium at different concentrations, and as a comparison a neural multipotent progenitor cell line was included in the analysis. The survival of tumour cells decreased dramatically when the lithium concentration was more than $12.8 \mathrm{mM}$, but no significant change for the immortalised neural progenitor cells was observed (Figure 1A). The $\mathrm{IC}_{50}$ values for the tumour cell lines varied between 6.5 to $20 \mu \mathrm{M}$ (Figure 1B). We further examined the combined effects of lithium and irradiation on DAOY cells, a medulloblastoma cell line which is resistant to irradiation. In this tumour cell line, cell viability decreased significantly in the presence of $10 \mathrm{mM}$ lithium $(p<0.01)$, and no protective effect of lithium on the tumour cells was observed (Figure 1C).

\section{Effects of lithium treatment on cell death in the DG after irradiation}

Pyknotic cells were detected in the SGZ $6 \mathrm{~h}$ after irradiation using H\&E staining (Figure 2A) and the number of the pyknotic cells was $19.8 \%$ lower after lithium treatment $(p<0.05)$ (Figure 2B). As expected, because of rapid clearance the overall number of pyknotic cells was lower $24 \mathrm{~h}$ after irradiation compared to the earlier $(6 \mathrm{~h})$ time point [32]. At this later time point, however, the number of pyknotic cells was higher in the lithium-treated group compared to the vehicle-treated group $(p<0.05)$ (Figure 2B), presumably indicating not only inhibited, but also some degree of delayed, cell death in the lithium-treated group. Similar tendencies were observed after TUNEL labelling (Figure 2C) and quantification of TUNEL-labelled cells (Figure 2D).

\section{Effects of lithium treatment on proliferation and differentiation in the DG}

The short-term effects of lithium treatment on proliferation and cell survival were investigated by counting BrdU- and Ki67-labelled cells. The number of BrdU-labelled cells was slightly decreased at $6 \mathrm{~h}$ and significantly decreased at $24 \mathrm{~h}$ after irradiation compared with non-irradiated controls, but no difference was seen between vehicle and lithium treatment groups (Figure 3A3C). Ki67-labelled cells decreased $6 \mathrm{~h}$ after irradiation compared to the non-irradiated controls, and this decrease was more pronounced $24 \mathrm{~h}$ after irradiation, but lithium had no effect on this irradiation-induced reduction of proliferating cells (Figure 3D-3E).

The long-term effects of lithium treatment on survival of BrdU-labelled cells and differentiation were investigated by counting and phenotyping BrdU-labelled cells 16 weeks after irradiation (Figure 4A). The total number of surviving BrdU-labelled cells per DG after 16 weeks in the non-irradiated lithium-treated group was $35.6 \%$ higher than in the vehicle-treated group ( $p<$ 0.01) (Figure 4B-4C). The number of surviving BrdUlabelled cells in the irradiated animals was decreased 

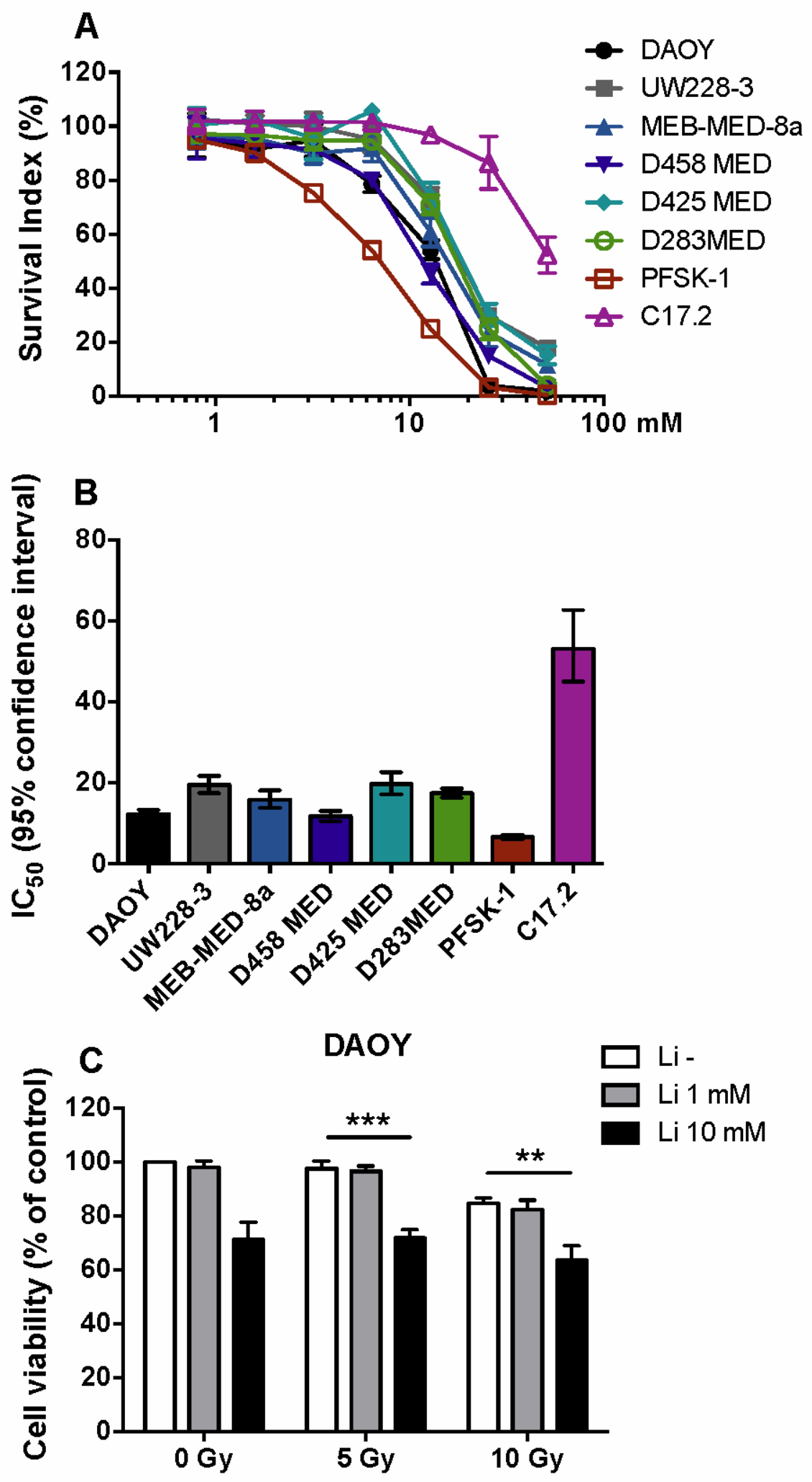

Figure 1: Dose-dependent lithium toxicity in vitro. A. Dose-response curve for lithium toxicity showing that the neural multipotent stem/progenitor cell line $\mathrm{C} 17.2$ is far more resistant to lithium toxicity than 7 different paediatric malignant brain tumour cell lines ( $72 \mathrm{~h}$ ). B. A bar graph showing the $\mathrm{IC}_{50}$ and $95 \%$ confidence interval values of lithium for the 8 different cell lines. The $\mathrm{IC}_{50}$ of the neural multipotent progenitor cell line is 2.7-8.1 times higher than that of the tumour cell lines. C. The effect of lithium and irradiation on cell survival of DAOY cells, demonstrating that lithium has no protective effect against irradiation. $* * p<0.01, * * * p<0.001$. 

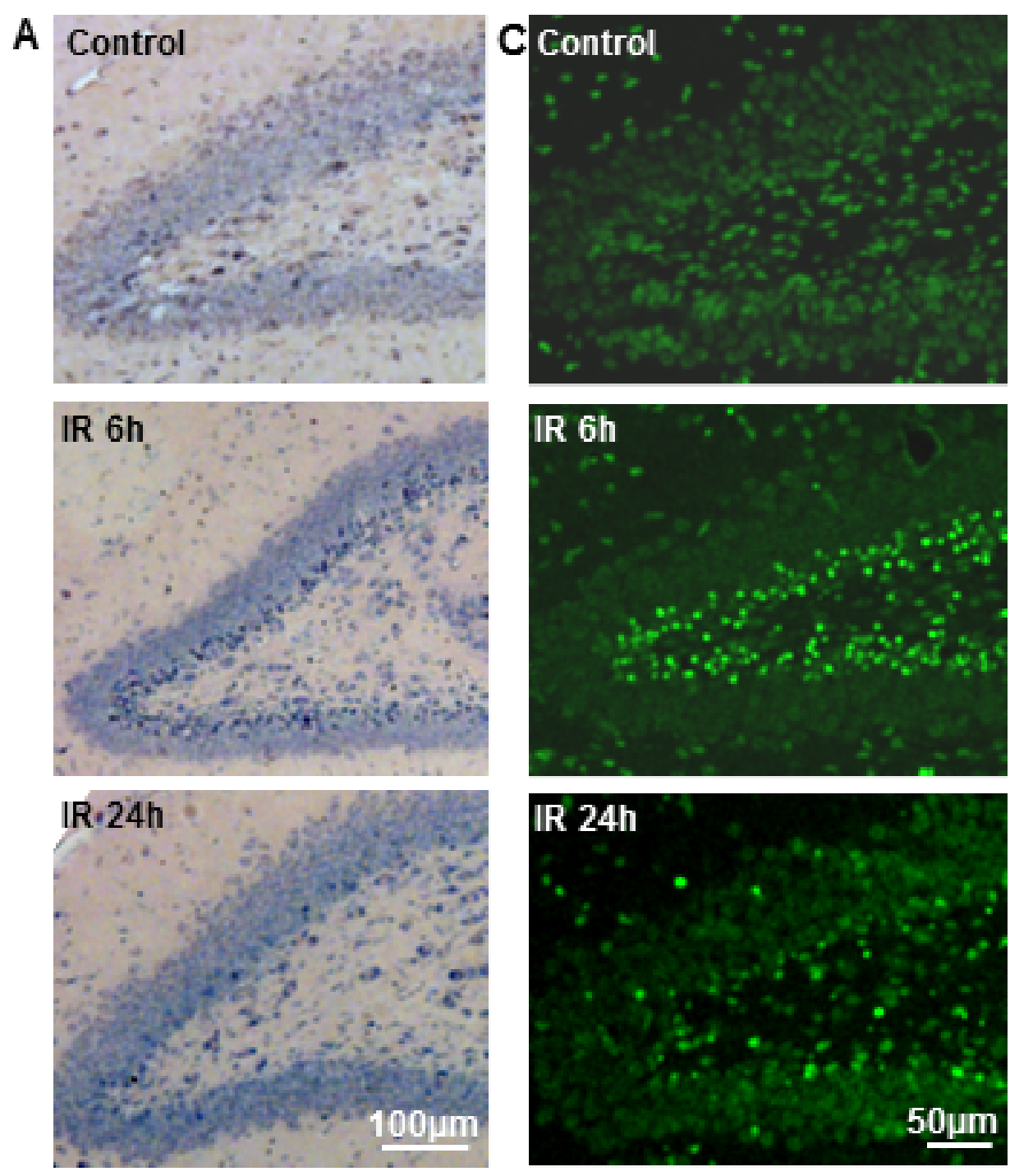

\section{B}

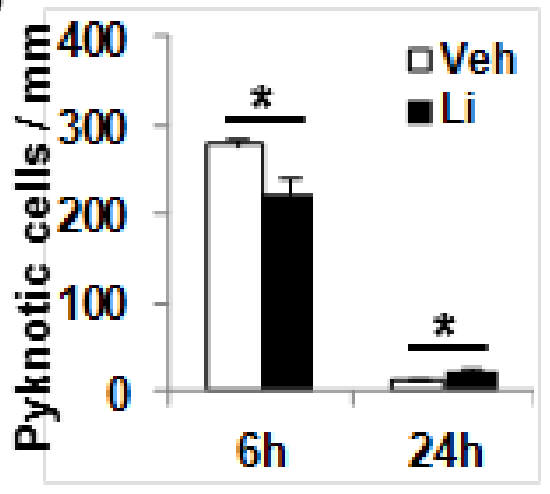

D

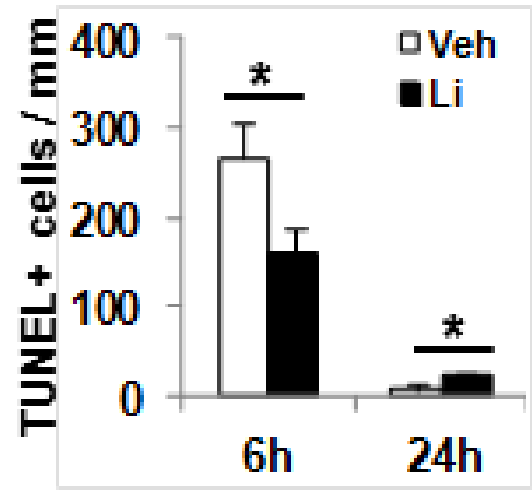

Figure 2: Cell death in the DG at $6 \mathbf{h}$ and $24 \mathbf{~ h}$ after irradiation. A. Representative photomicrograph of H\&E staining in the DG at $6 \mathrm{~h}$ and $24 \mathrm{~h}$ after irradiation. B. The bar graph shows the quantification of pyknotic cells in the SGZ at $6 \mathrm{~h}$ and $24 \mathrm{~h}$ after irradiation in both vehicle-treated and lithium-treated rats. C. Representative TUNNEL staining in the DG at $6 \mathrm{~h}$ and $24 \mathrm{~h}$ after irradiation. D. Quantification of TUNEL-labelled cells in the vehicle-treated and lithium-treated rats after irradiation. $n=6 /$ group for the $6 \mathrm{~h}$ vehicle and lithium treatment, $n=6$ for the vehicle group and $n=7$ for the lithium treatment group at 24 h. ${ }^{*} p<0.05$. 
dramatically compared with the non-irradiated controls, but the total number of surviving BrdU-labelled cells after irradiation was $50.1 \%$ higher in the lithium-treated group compared to the vehicle-treated group (Figure 4B$4 \mathrm{C})$. The phenotyping of newly generated cells surviving at least 16 weeks showed that neurogenesis (BrdU+/ $\mathrm{NeuN}+$ cells) was higher in lithium-treated animals, both in the non-irradiated (39.5\%) and irradiated rats (64.5\%) (Figure4D-4E). The number of newly generated astrocytes (BrdU+/S100+ cells) was not significantly different between lithium-treated and vehicle-treated non-irradiated rats, but it was higher (75.2\%) in the lithium-treated group compared to the vehicle-treated group after irradiation (Figure 4F). Increased numbers of neural stem cells $(\mathrm{BLBP}+$ cells) after lithium treatment was observed in non-irradiated, but not in irradiated, brains 16 weeks later (Figure 4G-4H). The ratio of neurogenesis to astrogenesis was not different between the lithium-treated and vehicletreated groups, indicating that lithium treatment resulted in increased overall survival of stem or progenitor cells (NSPCs) and did not specifically promote one cell fate over the other. The number of proliferating $(\mathrm{PHH} 3+)$ cells at this late time point was reduced by irradiation, but not altered by lithium (Figure 4I-4J). To further check

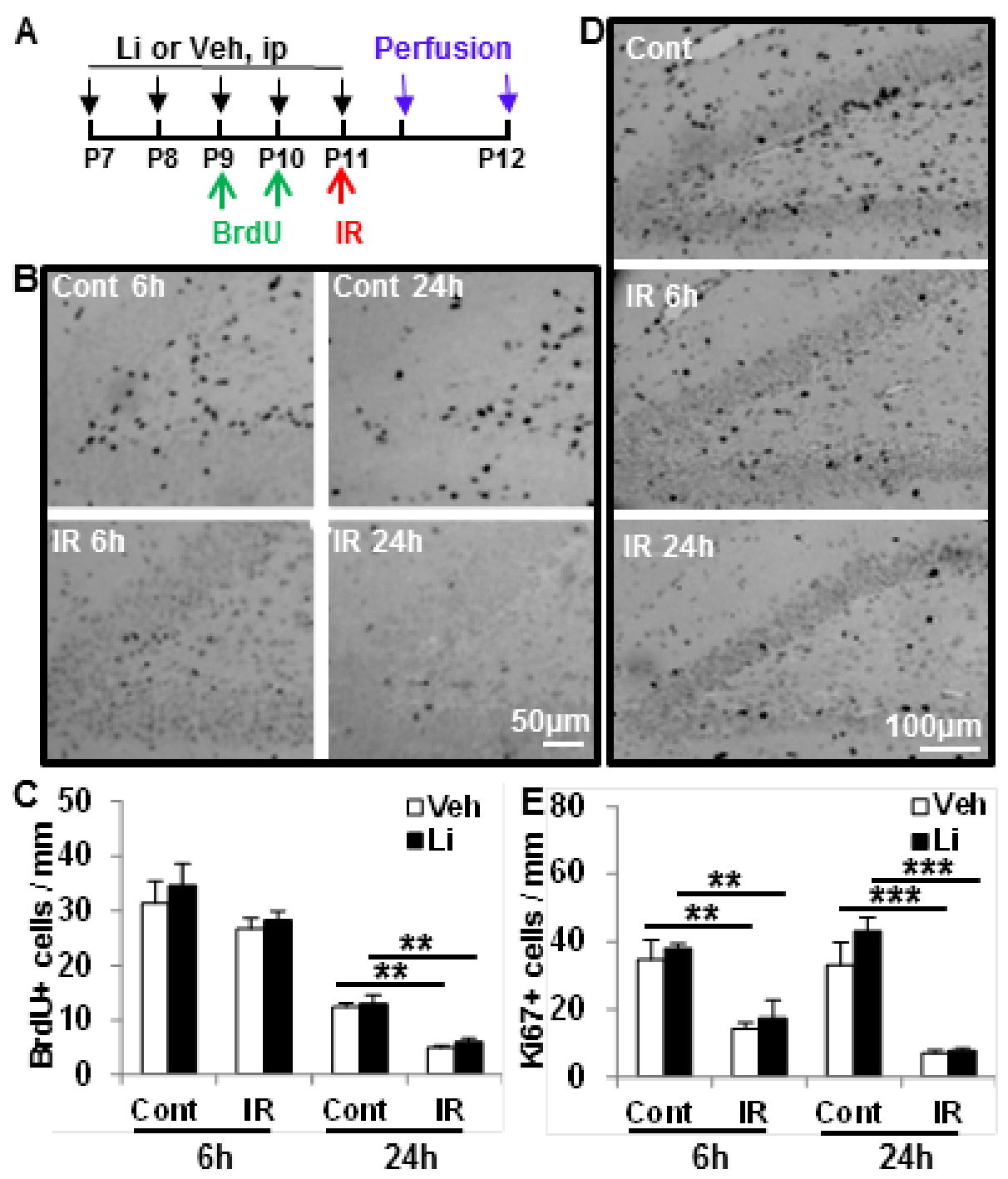

Figure 3: Short- term effect of lithium on cell proliferation. A. The study design. B. Representative photomicrographs of BrdU staining in the DG at $6 \mathrm{~h}$ and $24 \mathrm{~h}$ after irradiation. C. Quantification of BrdU-positive cells in the SGZ of the DG in the control (Cont) and ipsilateral hemisphere after irradiation (IR) in vehicle-treated and lithium-treated animals. D. Representative microphotographs of Ki67 staining in the SGZ at $6 \mathrm{~h}$ and $24 \mathrm{~h}$ after irradiation. E. Quantification of Ki67-positive cells in the SGZ of the DG in the control and irradiated rats with vehicle treatment and lithium treatment $(n=6$ /group for $6 \mathrm{~h}, n=6$ for the vehicle group and $n=7$ for the lithium group at $24 \mathrm{~h}) . * * * p<0.001$. 

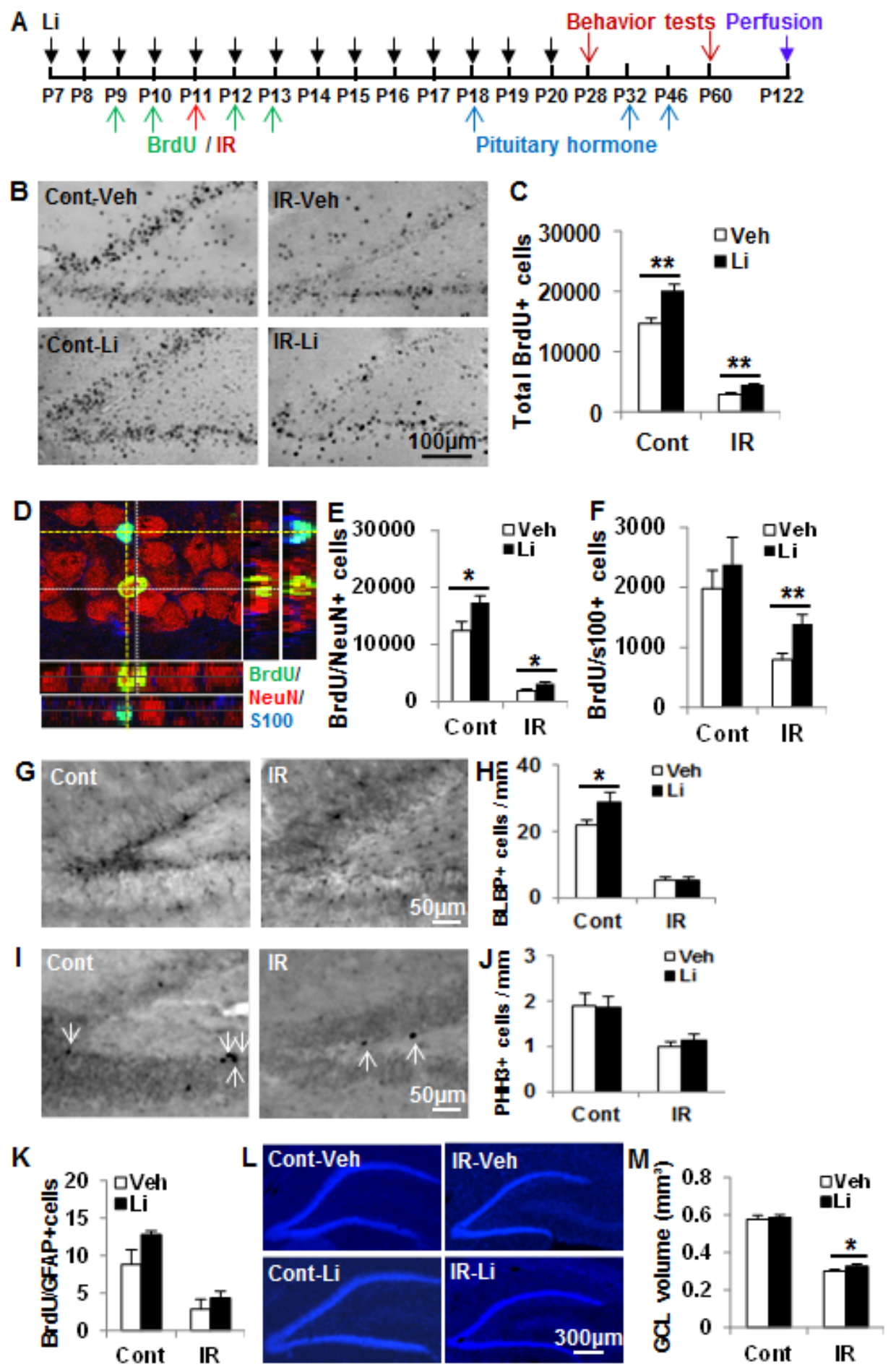

Figure 4: Effect of lithium on proliferated cell survival and differentiation after irradiation. A. The study design. B. Representative BrdU staining from the dorsal hippocampal level at 16 weeks after irradiation. C. Quantification of BrdU-labelled cells in the GZ of the DG at 16 weeks after irradiation. D. Representative BrdU-NeuN-S100 staining. E. The quantification of newborn neurons in the DG. F. The quantification of newborn astrocytes in the DG. G. Representative microphotographs of BLBP staining in the DG at 16 weeks after irradiation. H. The bar graph shows quantification of BLBP-positive cells in the SGZ of the DG. I. Representative microphotographs of PHH3 staining in the SGZ at 16 weeks after irradiation. J. The bar graph shows quantification of PHH3-positive cells in the SGZ of the DG. K. The graph shows the absolute numbers of BrdU-GFAP double-labelled cells in the SGZ of the DG at 16 weeks after irradiation. L. Representative DAPI staining of the DG of the hippocampus. M. Quantification of the granular cell layer (GCL) volume of the DG showing a reduction of about $44 \%$ in lithium-treated rats and $48 \%$ in vehicle-treated rats ( $n=14$ for control vehicle, $n=16$ for control lithium, $n=16$ for irradiation vehicle, $n=18$ for irradiation lithium). ${ }^{*} p<0.05, * * p<0.01$. 
if lithium had an effect on the neural stem cell pool, we performed BrdU-GFAP double labelling, and counted double-positive cells in the SGZ. Although there was a tendency towards an increase in the non-irradiated brains, as for BLBP, there was no significant difference between vehicle- and lithium-treated mice, neither in controls, nor in irradiated brains (Figure 4K). Hence, irradiation induced persistent inhibition of NSPC proliferation after
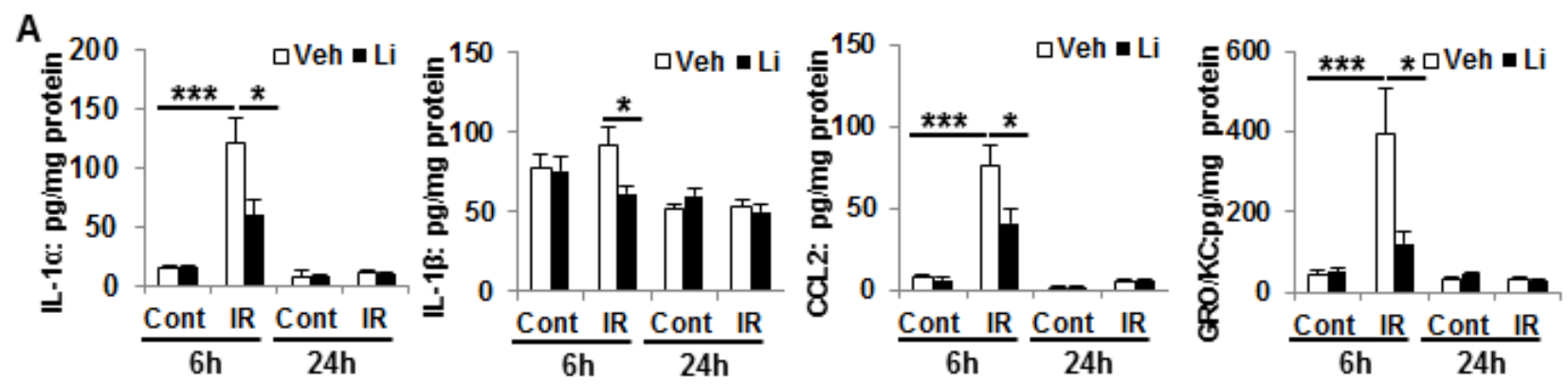

B
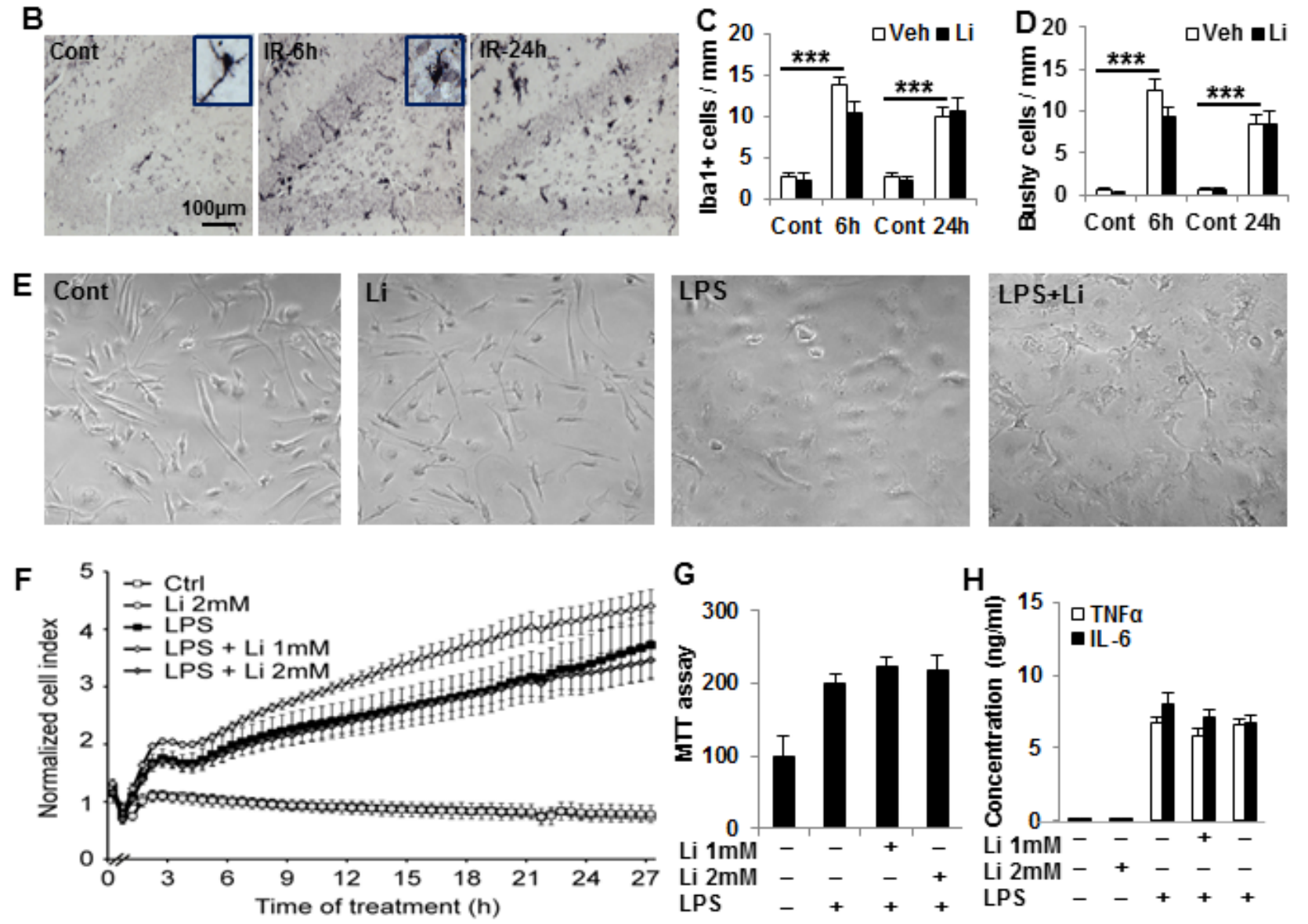

Figure 5: Lithium prevents irradiation-induced early inflammation in the hippocampus, but not effect on microglia activation in vivo and in vitro. A. IL- $1 \alpha, \mathrm{MCP}-1$, and $\mathrm{GRO} / \mathrm{KC}$ increased dramatically at $6 \mathrm{~h}$ after irradiation compared to the nonirradiated controls. Lithium treatment prevented increases in IL-1 $\alpha$, MCP-1, and GRO/KC (D). The level of IL- $1 \beta$ was lower in the irradiated pups with lithium treatment at $6 \mathrm{~h}$, but not at $24 \mathrm{~h}(n=5$ for $6 \mathrm{~h}$ control, $n=7$ for $6 \mathrm{~h}$ irradiation, $n=4$ for $24 \mathrm{~h}$ control, and $\mathrm{n}=$ 5 for $24 \mathrm{~h} \mathrm{IR}$ ). B. Representative Iba1 immunostaining of normal control and $6 \mathrm{~h}, 24 \mathrm{~h}$ after irradiation in the DG of hippocampus. C. Bar graph shows Ibal positive cells increased significantly after irradiation compared to no-irradiated controls. D. Quantification of bushy cells based on the Ibal staining and morphology. Most of the Ibal positive cells were bushy morphology after irradiation. E. Representative pictures of microglia morphology in vitro under the four different conditions. F. xCELLigence analysis of microglia cells treated with LPS and/or lithium. G. Viability (MTT) analysis of microglia treated with LPS and lithium. The number and/or size of microglia increased after LPS treatment, and lithium had no effect on this. H. A bar graph of TNF $\alpha$ and IL-6 concentrations in the microglia culture medium. LPS stimulates TNF $\alpha$ and IL- 6 secretion, and lithium had no apparent effect on this. ${ }^{*} p<0.05,{ }^{* * *} p<0.001$. 
irradiation, and lithium had no apparent effect on this in the irradiated rats, despite reduced cell death and increased neurogenesis and astrogenesis. The volumes of the GCL in the DG was measured based on DAPI staining (Figure 4L), and the volume was decreased by $48.1 \% 16$ weeks after irradiation in the vehicle-treated group and by $44.3 \%$ in the lithium-treated group. The total GCL volume was not significantly different in the non-irradiated control groups, but was $9.4 \%$ higher in the lithium-treated irradiated group compared to the vehicle-treated irradiated group $(p<0.05)$ (Figure 4M).

\section{Effects of lithium on microglia activation and inflammation in the hippocampus after irradiation}

Cytokines (IL-1 $\alpha$, IL-1 $\beta$ ) and chemokines (CCL2, $\mathrm{GRO} / \mathrm{KC}$ ) increased significantly in hippocampal tissue $6 \mathrm{~h}$ after irradiation, except IL-1 $\beta$, and lithium treatment prevented the irradiation-induced hippocampal inflammatory response (Figure 5A). The irradiationinduced inflammatory reaction was transient and had returned to non-irradiated control levels by $24 \mathrm{~h}$ after irradiation. Unlike the $6 \mathrm{~h}$ time point, there were no differences between vehicle-treated and lithium-treated groups at $24 \mathrm{~h}$ time point (Figure 5A). The number of microglia increased dramatically in the GCL after irradiation, and microglia were activated, as judged by their morphology, but lithium had no apparent effect on either of these two parameters (Figure 5B-5D). To further analyse the effects of lithium on microglia activation and inflammation, primary microglia were cultured, treated with lithium and stimulated with LPS. Cell numbers and morphological alterations were monitored by real-time impedance using an xCELLigence system. LPS induced a steady impedance increase, mainly attributed to changes in microglial shape, first detected $3 \mathrm{~h}$ following LPS exposure. This increase in cell index persisted during the following $24 \mathrm{~h}$ (Figure 5E-5F). Lithium treatment alone did not alter microglial shape under resting conditions. Moreover, pre-treatment with lithium for $24 \mathrm{~h}$ followed by LPS challenge did not change the LPS-induced cell index increase (Figure 5F). Furthermore, MTT cell proliferation analysis showed that lithium pre- and co-treatment did not affect LPS-induced microglia proliferation (Figure 5G). Neither IL-6 nor TNF- $\alpha$ (Figure 5H) were detected in the medium of non-stimulated microglia, but both of them increased in response to LPS, and lithium treatment had no effect on these cytokine levels. In summary, lithium did not appear to have any direct, anti-inflammatory effect of microglia. This indicates that the reduced inflammatory response in vivo likely was secondary to the reduced injury.

Effects of lithium on body weight gain and pituitaryrelated hormones after irradiation Body weight gain was delayed in irradiated rats, detectable from about 4 weeks after irradiation (Figure 6A, 6B). This effect was persistent, but lithium treatment had no influence on body weight gain, neither in normal control rats, nor in irradiated animals. Serum creatinine levels were increased during the rapid growth period, but no difference was seen between the vehicle-treated and lithium-treated animals at any time point (data not shown). Pituitaryrelated hormones, including thyroid-stimulating hormone (TSH), ACTH, prolactin, growth hormone $(\mathrm{GH})$ and brain-derived neurotrophic factor (BDNF) were assayed in serum at different time points after irradiation. All these hormones increased 2- to 10-fold when the body growth rate increased, but the normal, growth-related increase in pituitary hormones was reduced or even abolished in irradiated rats (Figure 6C). Lithium treatment restored $\mathrm{TSH}$ and GH levels, and reduced the injury-induced BDNF increase [33], indicating that the injury to the hypothalamus-pituitary axis was ameliorated, thereby reducing the risk of developing hypothyroidism and $\mathrm{GH}$ deficiency (Figure 6D).

\section{Effect of lithium on motor activity and recognition memory}

Motor activity increased with age, as indicated by running distance $(p<0.0001)$ (Figure 7A-7B). The accumulated running distance in P28 rats was 74.5\% greater for the irradiated rats compared to the nonirradiated controls $(p<0.001)$ and $35.6 \%$ greater for P60 rats $(p<0.001)$. Lithium treatment reduced irradiationinduced hyperactivity in P60 rats $(p<0.01)$ but not in P28 rats. The time spent in the open central zone was $71.4 \%$ greater in the irradiated rats compared to the non-irradiated controls $(p<0.05)$. Lithium treatment normalised the time spent in the open central zone in irradiated $\mathrm{P} 60$ rats $(p<$ 0.05 ) (Figure 7C). Memory function, as judged by novel object recognition, increased with age between P28 and P60 in normal control rats $(p<0.05)$. Irradiation had no obvious effect on recognition memory in P28 rats, but there was a substantial decrease in memory function in irradiated P60 rats, and this deficit was normalized by lithium treatment $(p<0.05)$ (Figure 7D).

\section{DISCUSSION}

In this study we found that lithium was toxic to all the 7 different human paediatric brain tumour cell lines tested, but the $\mathrm{IC}_{50}$ lithium concentrations in vitro were in the order of one magnitude higher than the therapeutical serum concentrations used. The intra- and extracellular lithium concentrations required to obtain the observed effects in the brain are not known, but we recently showed that serum concentrations of $1.2 \mathrm{mM}$ in mice yielded brain tissue concentrations in the range of 
$0.82-0.05 \mathrm{mM}$, where the highest concentrations were observed in the neurogenic regions [34]. Lithium did not appear to protect medulloblastoma cells from radiationinduced cell death in vitro. This is line with the findings using mouse hippocampal neuronal HT-22 cells and mouse glioma cells [23]. Lithium has even been shown to abrogate TP53-associated radiation resistance in medulloblastomas, thereby enhancing the anti-tumour effects of radiotherapy [29]. However, we have previously demonstrated the ability of lithium to reduce radiationinduced DNA damage [28]. As such, additional in vivo studies will be required to assess if radiating tumours in the presence of lithium could increase risk of tumour recurrence from any surviving malignant cells. Cohen and co-workers observed an inverse trend of non-epithelial cancer incidence with lithium dose in patients treated with lithium carbonate for bipolar disorder [35]. Furthermore, Martinsson and co-workers found an increased risk of respiratory, gastrointestinal, and endocrine cancer in patients with bipolar disorder without lithium treatment [36]. Lithium has been used for treatment of bipolar or related disorders, also in children [37], and a recent study reported increased hippocampal volumes in lithium-treated adolescents [38]. Whereas lithium treatment for bipolar disorder is chronic, the herewith proposed treatment to prevent irradiation-induced late effects would be limited in time to the weeks of radiotherapy and could be easily monitored on a daily basis. The proposed treatment may be even be extended beyond the duration of radiotherapy to counteract degeneration and promote regeneration [9, $26,30]$. This has been tried in a handful of cases of TP53mutated medulloblastoma [29], where lithium was used as a radiosensitizer, administered two weeks prior to, during and one month after radiotherapy, without any signs of toxicity [39] (Eric Bouffet, personal communication). Taken together, there is much evidence that lithium
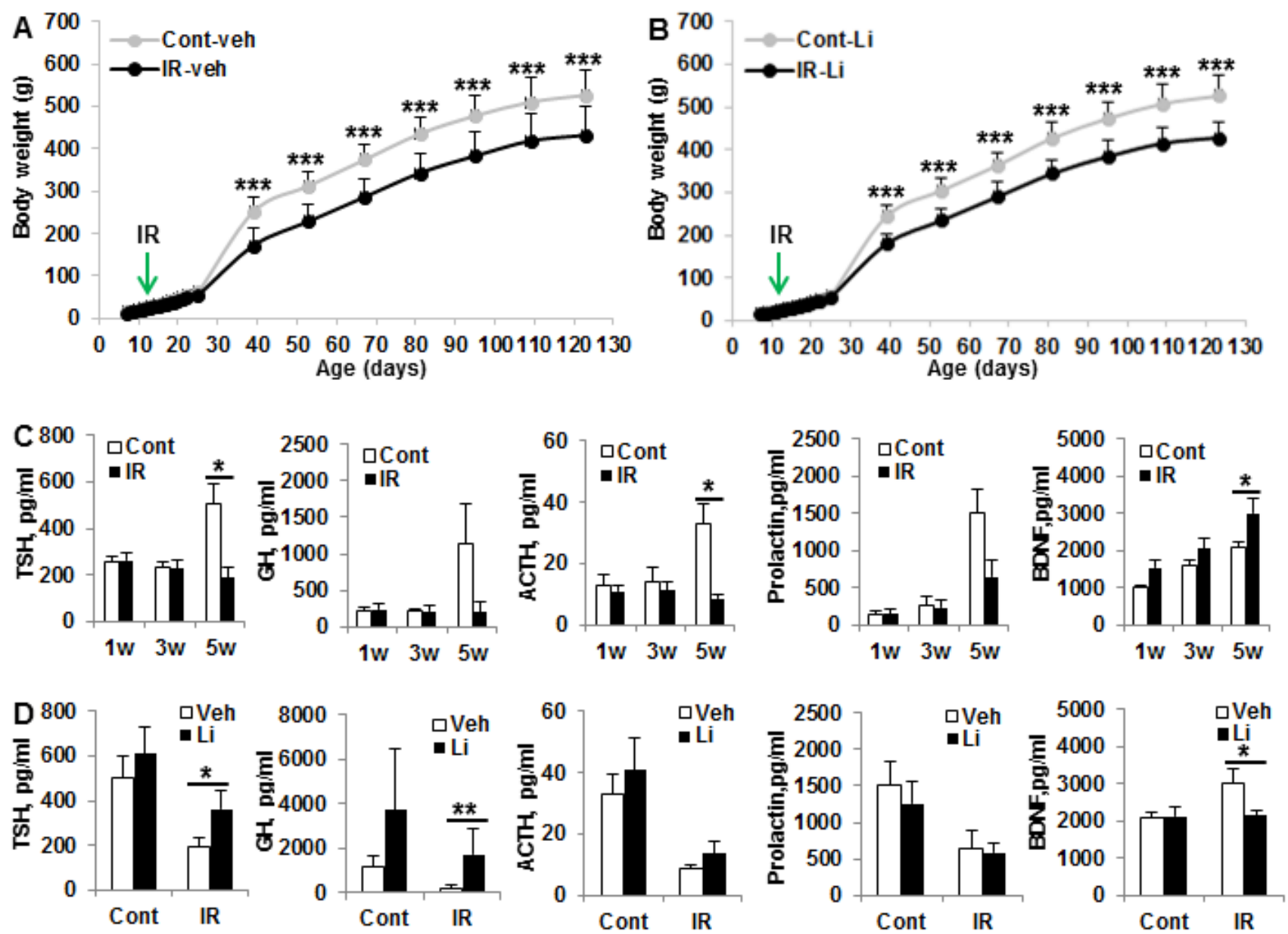

Figure 6: Effect of lithium treatment on pituitary hormones and body weight gain. A. Body weight in the vehicle-treated control and irradiated rats showed body weight gain was slow at 4 weeks, and this difference was still significant at 16 weeks after irradiation. B. Similar trend in body weight gain in lithium-treated rats as for the vehicle-treated rats $(n=14$ for control vehicle, $n=16$ for control lithium, $n=16$ for irradiation vehicle, and $n=18$ for irradiation lithium). C. The pituitary hormones TSH, ACTH, prolactin and BDNF in serum increased with age and were significantly higher at about 6 weeks after birth, and irradiation prevented the developmentally associated increases in pituitary hormones. D. Lithium treatment prevented irradiation-induced pituitary TSH reduction and BDNF increase at 5 weeks after irradiation ( $n=6 /$ group). ${ }^{*} p<0.05, * * p<0.01, * * * p<0.001$ 
does not protect tumour cells, rather the opposite. With the information at hand we cannot distinguish between possible effects on quiescent and proliferating tumour cells though.

Irradiation has been shown to have multiple deleterious effects on the brain that are age- and radiation dose-dependent [40]. Neurocognitive impairments in both rodents and humans are associated with neural stem cell dysfunction, inflammation, and demyelination [4143]. The neurogenic regions are particularly susceptible to irradiation $[10,32,44]$. Previously we showed that moderate, clinically relevant doses of irradiation to developing rodent brains caused extensive damage to neural stem and progenitor cells and significant reduction in the size of the neurogenic areas of the brain $[32,45]$. Loss of neural stem and progenitor cells in the hippocampus is associated with impairment of cognitive function following irradiation in rodents, and possibly also in humans [41, 46, 47], and prevention of radiation-induced stem cell death can ameliorate cognitive dysfunction $[6,11,15]$. Two previous studies have demonstrated reduced neurogenesis and cognitive performance in irradiated mice and amelioration of these deficits by lithium $[9,23]$. In vitro, lithium was shown to increase proliferation of hippocampal NSPCs and rescue irradiation-induced cell cycle arrest [28]. In this study, we found that lithium treatment prevented not only the radiation-induced cognitive deficits but also signs of hypothalamus-pituitary dysfunction without any apparent toxic effects. The doses used in this and other studies are in the same range as those used for humans, and no toxicity was observed. These results strongly suggest a potential of lithium treatment concomitant with cranial radiotherapy to ameliorate the irradiation-induced brain injury and cognitive deficits.

Inflammation plays an important role in brain injury, including after irradiation [45, 48, 49]. Radiation has been reported to activate microglia and to increase the expression of cytotoxic molecules such as proinflammatory cytokines and chemokines in the brain, and these have been implicated in radiotherapyassociated brain damage [9]. Neuroinflammation has been consistently implicated in the pathogenesis of radiation-induced cognitive decline $[45,48,50,51]$. In
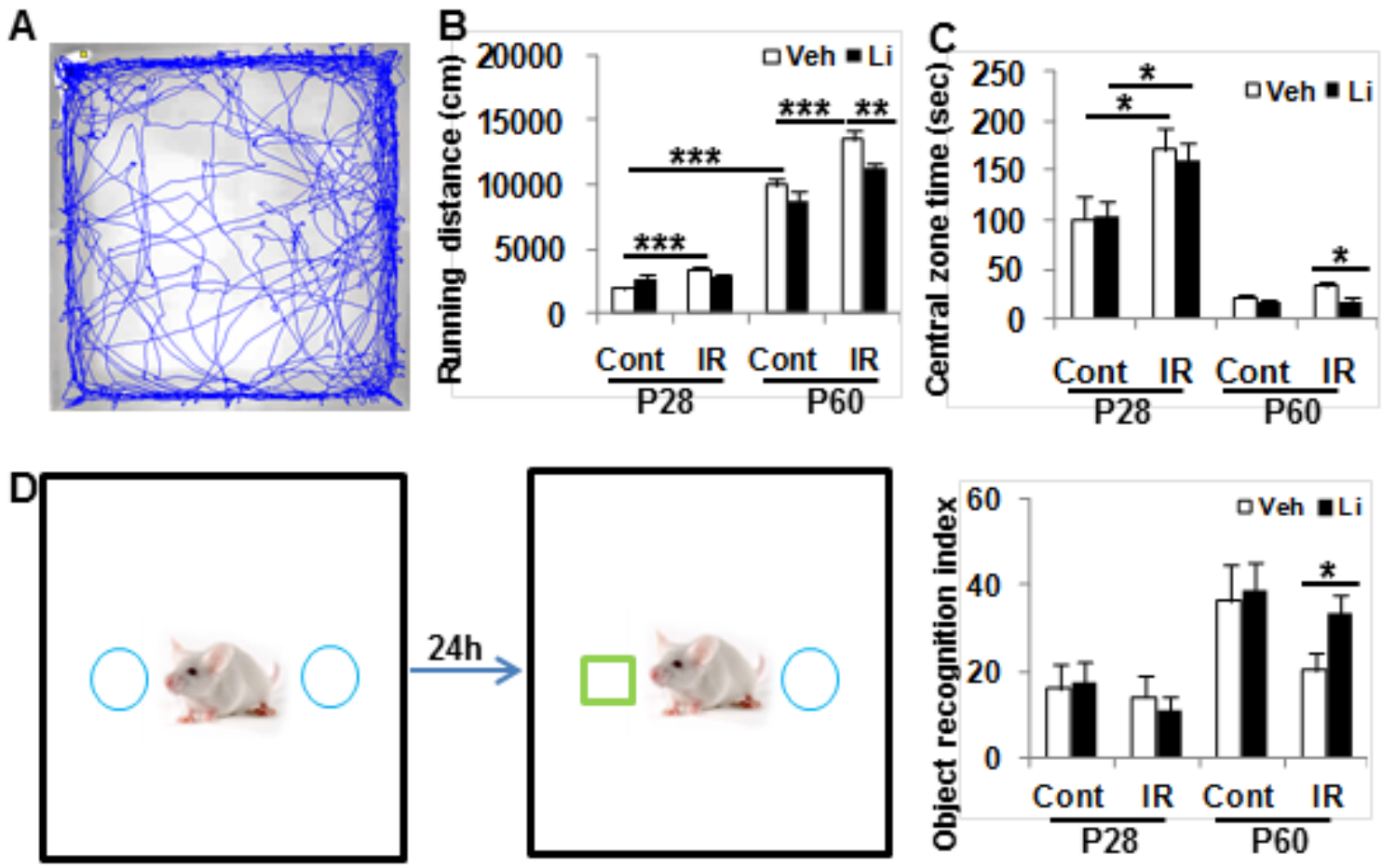

Figure 7: Behavioural tests. A. Open field tests show the accumulated distances moved over 20 min at P28 and P60. B. The irradiated rats were more active than the controls. Lithium treatment normalized the motor activity. C. Accumulated time spent in the open central zone in a 20-min open field test. The irradiated rats spent more time in the open central zone at P28 compare to non-irradiated controls. Lithium treatment reduced time spent in the open central zone in the irradiated rats at P60. D. The novel object recognition test showed that irradiation prevented recognition development and that lithium treatment normalized the irradiation-induced recognition deficit. $n=$ 14 for control vehicle, $n=16$ for control lithium, $n=16$ for irradiation vehicle, and $n=18$ for irradiation lithium. ${ }^{*} p<0.05$, ** $p<0.01$, $* * * \mathrm{p}<0.001$. 
the current study, lithium treatment prevented irradiationinduced acute inflammatory reactions $6 \mathrm{~h}$ after irradiation, and the same tendency was seen for cell death in the hippocampus. Because dying cells elicit inflammatory responses and because reduced cell death would result in attenuated inflammatory reactions, the decreased inflammation seen after lithium treatment could be secondary to reduced injury. This is supported by our finding that microglia activation in vitro by LPS was not affected by lithium treatment. Alternatively, it is possible that lithium-mediated inhibition of GSK3 $\beta$ in microglia indirectly restores inflammation-induced down-regulation of antioxidant capacity in astrocytes and thereby reduces cell death following oxidative stress [52].

In this study, lithium was administered before and after irradiation. Cell death was prevented or delayed at 6 hours and 24 hours after irradiation, and the inflammatory response, as indicated by cytokine and chemokine expression, was reduced at 6 hours after irradiation. These data indicate protective effects of lithium administration prior to irradiation. We previously showed that delayed lithium injection, 5 days after injury, could increase neurogenesis and decrease chronic inflammation in a model of hypoxic-ischemic brain injury [31]. So long as lithium administration during radiation does not promote subsequent tumour recurrence, our data suggest that cognitive benefits of lithium may be optimised if target serum concentrations are reached prior to radiotherapy, and maintained until a month or so after the end of the radiation treatment, as in the trial mentioned above, to maximise the benefit.

In addition to the direct effect of irradiation on neurogenesis and oxidative stress, cranial irradiation also has systemic effects on the entire body through radiation-induced endocrinopathy [53]. Growth hormone deficiency and hypothyroidism (central as well as peripheral) are common in survivors of paediatric brain tumours treated with radiotherapy $[54,55]$. It has been shown in adult animals that cranial radiation induces deficits in pituitary weight and pituitary growth hormones, and that these changes are greater in younger adult rats [12]. The influence on the juvenile, still developing brain should, therefore, be even more pronounced. Our results show that the levels of pituitary-related hormones were substantially lower than in controls 5 weeks after irradiation, concurrent with reduced body weight gain in the irradiated rats. Lithium treatment prevented the $\mathrm{TSH}$ and $\mathrm{GH}$ reductions in the irradiated group, but not the reduced body weight gain. Increased BDNF levels, indicative of hypothalamic/pituitary stress [33], were also prevented by lithium treatment in irradiated rats. This indicates that lithium treatment can ameliorate irradiationinduced hypothalamus-pituitary functional deficits, and the underlying mechanisms need to be investigated further.

In summary, we found that treatment of rats with lithium in conjunction with cranial irradiation prevents
NSPC death, stimulates NSPC proliferation and survival, reduces the cognitive decline and ameliorates the negative effects on the hypothalamus-pituitary axis. We also found that lithium is toxic to human paediatric brain tumour cells, but not neural stem cells, in vitro, and that lithium does not protect the brain tumour cells against irradiation. Lithium therefore holds great potential both as an adjuvant to radiotherapy as well as treatment to ameliorate the cognitive decline and possibly endocrine dysfunctions observed in survivors of paediatric malignant brain tumours.

\section{MATERIALS AND METHODS}

\section{Tumour cell line culture}

Human medulloblastoma wild-type TP53 cell lines (D283 MED, D425 MED, D458 MED, MED-MED8a) and TP53 mutant cell lines (DAOY and UW228-3) or primitive neuroectodermal tumour (PFSK-1) cell lines and a murine neural multipotent progenitor cell line (C17.2) were used. DAOY, D283MED and PFSK-1 were purchased from ATCC. The other cell lines were kindly provided by M Nistér (D425 MED, D458 MED, MED-MED-8a and UW228-3) or T Ringstedt (C17.2). The cell lines were cultured in minimum essential media (MEM; DAOY, D283 MED), RPMI-1640 (PFSK-1), Dulbecco's Modified Eagle's Medium (DMEM; MEBMED-8A, C17.2), Richter's improved MEM with zinc/ DMEM (IMEMZO/DMEM; D425 MED and D458 MED), $\mathrm{DMEM} / \mathrm{F} 12$ (UW228-3), at $37^{\circ} \mathrm{C}$ in a humidified $5 \%$ $\mathrm{CO}_{2}$ atmosphere. Medium was supplemented with $15 \%$ (C17.2) or $10 \%$ foetal calf serum (FCS) (GIBCO), and $2 \mathrm{mM}$ L-glutamine, $100 \mathrm{IU} / \mathrm{mL}$ penicillin $\mathrm{G}$, and $100 \mu \mathrm{g} /$ $\mathrm{mL}$ streptomycin. All media were purchases from GIBCO. Experiments were executed in Opti-MEM supplemented with glutamine and antibiotics. The identities of the human tumour cell lines were verified by short tandem repeat genetic profiling using the AmpFISTR ${ }^{\circledR}$ Identifiler $^{\circledR}$ PCR Amplification Kit (Applied Biosystems) and all cell lines were used in passages below 25 .

The effects of lithium chloride and radiation on cell growth were determined using a colorimetric formazanbased cell viability assay (WST-1; Roche) according to the manufactures description. Cells were seeded into 96-well plates $(3,000-10,000$ cells/well) left to attach and then treated with lithium chloride and incubated for $72 \mathrm{~h}$; in the combined experiments, cells were first treated with lithium chloride $(1$ or $10 \mathrm{mM})$, irradiated using a ${ }^{60} \mathrm{Co}$ radiation source ( 5 or $10 \mathrm{~Gy}$ ) the day after and then incubated for another $72 \mathrm{~h}$ before analysis. All concentrations were tested in triplicate and the experiments were repeated at least three times. IC50 values were calculated as described earlier [56], using GraphPad Prism (GraphPad Software, 
San Diego, CA, USA) from log concentration - effect curves (cell viability \%) by using nonlinear regression. Effect on cell viability was determined by using a colourimetric formazan-based cell viability assay (WST1; Roche) after 72 hours incubation with lithium. WST-1 measures cell growth as well as inhibition, and is based on the cleavage of the tetrazolium salt WST-1 to formazan by cellular mitochondrial dehydrogenases. Expansion in the number of viable cells leads to an increase in the activity of the mitochondrial dehydrogenases, which in turn leads to increased amounts of formazan dye formed. The formazan dye produced by viable cells can be quantified by measuring the absorbance (at $440 \mathrm{~nm}$ ). Background control absorbance was measured at $650 \mathrm{nM}$, absorbance at this wavelength was subtracted from the absorbance at $440 \mathrm{~nm}$. Lithium was tested in concentrations ranging from 51.2 to $0.8 \mathrm{mM}$, diluted in seven twofold serial dilution steps. Cell viability was calculated absorbance in experimental wells in percent of control wells, with blank values subtracted.

\section{Primary microglia culture}

Microglia cultures were prepared as previously described [57]. Briefly, brains were removed from 1- to 3-day-old C57Bl/6 pups, incubated for $15 \mathrm{~min}$ in $1 \mathrm{mg} / \mathrm{ml}$ trypsin, followed by $2 \mathrm{~min}$ of $1 \mathrm{mg} / \mathrm{ml}$ trypsin inhibitor, rinsed, dissociated and cultured in DMEM consisting of Hams F12 (50/50), supplemented with 10\% FCS, 100 $\mathrm{U} / \mathrm{mL}$ penicillin, $100 \mu \mathrm{g} / \mathrm{mL}$ streptomycin and $2 \mathrm{mM}$ glutamine. The medium was replaced after 2 days. After 10-14 days, flasks were mechanically shaken for 60 min, $150 \mathrm{rpm}$ to release microglia into the supernatant, subsequently subcultured into uncoated 96-well plates (15,000-17,000 cells/well). They were kept in $70 \%$ astrocyte-conditioned medium and 30\% fresh DMEM/F12 supplemented with $10 \% \mathrm{FCS}, 100 \mathrm{U} / \mathrm{mL}$ penicillin, 100 $\mu \mathrm{g} / \mathrm{mL}$ streptomycin and $2 \mathrm{mM}$ glutamine for $1-2$ days to achieve microglia in a quiescent state. Medium was then changed to fresh medium as above or cells were incubated with different concentrations of lithium chloride (1-2 $\mathrm{mM}$ ) for $24 \mathrm{~h}$ followed by $200 \mathrm{ng} / \mathrm{ml}$ lipopolysaccharide (LPS, Sigma). After another $24 \mathrm{~h}$, medium was collected for TNF- $\alpha$ and IL-6 assay using the Duoset ELISA system according to the manufacturer's instructions (R\&D, Minneapolis). Quantification of cell viability was performed using MTT reduction assay at $0.5 \mathrm{mg} / \mathrm{mL}$ for 1 $\mathrm{h}$. The reaction was terminated by removing the media and freezing the plate at $-80^{\circ} \mathrm{C}$ for at least $1 \mathrm{~h}$. DMSO solvent was added to each well for $1 \mathrm{~h}$ under shaking conditions at $37^{\circ} \mathrm{C}$. The absorbance of each well was determined with an automated FLUOstar Optima reader at $570 \mathrm{~nm}$ with a reference filter at $630 \mathrm{~nm}$.

\section{Animal irradiation procedure}

A linear accelerator with $4 \mathrm{MV}$ nominal photon energy and a dose rate of $2.3 \mathrm{~Gy} / \mathrm{min}$ was used [58 ]. Postnatal day 11 (P11) male Wistar rat pups (Charles River, Germany) were anesthetized with an intraperitoneal injection of $50 \mathrm{mg} / \mathrm{kg}$ tribromoethanol. The animals were placed in a prone position with their head in the gantry of an expanded polystyrene bed. The whole brain was irradiated with a radiation field of $2 \mathrm{~cm} \times 2 \mathrm{~cm}$. A single absorbed dose of 6 Gy was administered. Using the linear-quadratic model[59] and an $\alpha / \beta$ ratio of 3 for late effects in normal brain tissue, the acute exposure of $6 \mathrm{~Gy}$ is approximately equivalent to 12 Gy when delivered in repeated 2 Gy fractions, thereby representing a clinically relevant, moderate radiation dose. The radiation dose administered to the brain and spinal cord of children with malignant brain tumours is usually higher. In the current medulloblastoma protocol (PNET 5), for example, a craniospinal dose of $23.4 \mathrm{~Gy}$ is combined with a 30.6 Gy boost to the tumour bed. From a practical point of view, for proof of principle, a single dose of 6-8 Gy is often used in rodent models [32]. Sham control animals were anaesthetized but not subjected to irradiation. This study was approved by the Gothenburg Committee of the Swedish Animal Welfare Agency (202-2012).

\section{Lithium administration}

Lithium chloride (Aldrich, USA) was dissolved in normal saline and injected at a dose of $2 \mathrm{mmol} / \mathrm{kg}$ intraperitoneally at P7. For the short-term study, this was followed by $1 \mathrm{mmol} / \mathrm{kg}$ injections at $24 \mathrm{~h}$ intervals for four successive days until irradiation at P11. Pups were then sacrificed at $6 \mathrm{~h}$ or $24 \mathrm{~h}$ after irradiation. For the longterm study, the same initial protocol was used but after irradiation at P11 the rats were injected with $1 \mathrm{mmol} /$ $\mathrm{kg}$ lithium chloride every $24 \mathrm{~h}$ for another 10 days [30]. These rats were sacrificed at 16 weeks after irradiation.

\section{BrdU administration}

BrdU (5 mg/mL dissolved in 0.9\% saline; Roche, Germany) was freshly prepared prior to use and injected intraperitoneally $(50 \mathrm{mg} / \mathrm{kg})$ once at P9 and once at P10. The rat pups were sacrificed $6 \mathrm{~h}$ or $24 \mathrm{~h}$ after irradiation at $\mathrm{P} 11$. For the long-term evaluation, BrdU injections were also given on P12 and P13 after irradiation at P11 and were sacrificed at 16 weeks after irradiation. 


\section{Determination of cytokine and chemokine levels in the hippocampus}

The hippocampus was collected from both control and irradiated pups at $6 \mathrm{~h}$ or $24 \mathrm{~h}$ after irradiation and was homogenized in $0.1 \mathrm{M}$ PBS containing a cocktail of protease inhibitors (Roche) and 1\% phosphatase inhibitor cocktail 2 (Sigma). The sample was homogenized and centrifuged at $10000 \mathrm{~g}$ for $15 \mathrm{~min}$ at $4^{\circ} \mathrm{C}$. The supernatant was collected and stored at $-80^{\circ} \mathrm{C}$ for the cytokine/ chemokine assay. The total protein concentration was measured by using the BCA method. Concentrations of IL- $1 \alpha$, IL- $1 \beta, \mathrm{GRO} / \mathrm{KC}$, and MCP-1 were simultaneously quantified using a MILLIPLEX ${ }^{\circledR}$ MAP rat cytokine kit (Millipore).

\section{Pituitary-related hormone assay}

Blood samples were collected from the tail in the morning around $10 \mathrm{am}$ and placed at room temperature for about $60 \mathrm{~min}$ to coagulate and centrifuged at $1000 \mathrm{~g}$ for $10 \mathrm{~min}$. The serum was then removed and stored at $-80^{\circ} \mathrm{C}$. The samples were analysed using the MILLIPLEX ${ }^{\circledR}$ MAP rat pituitary magnetic bead panel assay kit (Millipore).

\section{Behavioural tests}

Motor activity patterns were analysed with an open field system at about P28 and P60 of age [31]. Briefly, rats were placed into the centre of an unfamiliar $100 \mathrm{~cm}$ $\times 100 \mathrm{~cm}$ dark grey-coloured Plexiglas open-field arena, and the total movement distance was recorded for $20 \mathrm{~min}$. The centre of the animal's body was defined as the point for tracking zone entries. The recorded video was analysed using the EthoVision 3.1 video-tracking software. The central zone was defined as a $30 \mathrm{~cm} \times 30 \mathrm{~cm}$ area in the centre of the arena. The anxiety-related activity was assayed as the amount of time spent within the central zone.

Object recognition was tested the next day in the open-field box. The test consisted of two trials with an interval of $24 \mathrm{~h}$. During the first trial, the animals were placed in the box containing two identical objects for 5 $\min$. For the second trial, one of the objects presented in the first trial was replaced by a novel object. The animals were placed back in the box for $5 \mathrm{~min}$, and the total time spent exploring each object was determined. Data are expressed as the recognition memory index [60].

\section{Immunohistochemistry}

The paraffin embedded left hemisphere was cut into $5 \mu \mathrm{m}$ sagittal sections for haematoxylin and eosin $(\mathrm{H} \& \mathrm{E})$ as well as cell death-related markers and stem/ progenitor cell proliferation markers. Monoclonal rat antiBrdU (1:200, AbD Serotec) or mouse anti-Ki67 (1:150, Novocastra) primary antibodies were applied and followed by biotinylated secondary antibody (1:500; Jackson ImmunoResearch) for $60 \mathrm{~min}$ at room temperature. Endogenous peroxidase activity was blocked with 3\% $\mathrm{H}_{2} \mathrm{O}_{2}$ in PBS for $10 \mathrm{~min}$. This was followed by incubation with Vectastain ABC. For the TUNEL labelling, the sections were incubated with $3 \%$ bovine serum albumin in $0.1 \mathrm{M}$ Tris- $\mathrm{HCl}(\mathrm{pH} 7.5)$ for $30 \mathrm{~min}$ followed by 50 $\mu 1$ TUNEL reaction mixture for $60 \mathrm{~min}$ at $37^{\circ} \mathrm{C}$ in a humidified chamber. After washing, the sections were mounted using Vectashield mounting medium.

For the long-term study, sagittal sections $(30 \mu \mathrm{m})$ were used for stem cell proliferation and differentiation staining. BrdU labelling was performed on free-floating sections. After blocking with 3\% donkey serum, the sections were incubated with rat anti-BrdU (1:200; AbD Serotec) overnight at $4^{\circ} \mathrm{C}$. After rinsing, sections were incubated for $2 \mathrm{~h}$ at room temperature with biotinylated donkey anti-mouse (1:1000; Jackson ImmunoResearch). This was followed by incubation with Vectastain ABC and then detection solution. For phospho-histone H3 (PHH3) staining and brain lipid binding protein (BLBP) staining, the sections were incubated with rabbit anti-PHH3 (1:200, Upstate) and rabbit anti-BLBP (1:600, ABN14; Millipore) in blocking solution for $16 \mathrm{~h}$ at $4{ }^{\circ} \mathrm{C}$. After rinsing, sections were incubated for $2 \mathrm{~h}$ at room temperature with biotinylated donkey anti-rabbit secondary antibody $(1: 500)$.

The phenotypes of BrdU-labelled cells were determined using double immunofluorescent staining. BrdU staining was performed as above followed by either mouse anti-NeuN monoclonal antibody $(1: 200$, Chemicon) and rabbit anti-S-100 $\beta$ (1:1000; Swant) in PBS. After washing, the sections were incubated with Alexa 488 donkey anti-rat IgG combined with Alexa 555 donkey anti-mouse IgG and Alexa 647 donkey antirabbit $\operatorname{IgG}(1: 1000$, Jackson ImmunoResearch) secondary antibodies. For double labelling of BrdU-GFAP, BrdU staining was performed as above and followed by goat anti-GFAP antibody (1:100; clone: SC-6170, Santa Cruz Biotechnology, Texas, USA) in PBS at $4^{\circ} \mathrm{C}$ for overnight. After washing, the sections were incubated with secondary antibodies, Alexa Fluor 488 donkey anti-rat $\operatorname{IgG}(\mathrm{H}+$ L), combined with either Alexa Fluor 546 donkey antigoat $\operatorname{IgG}(\mathrm{H}+\mathrm{L})(1: 1000$, Jackson ImmunoResearch) at $20^{\circ} \mathrm{C}$ for $60 \mathrm{~min}$. After washing, the sections were mounted using ProLong Gold antifade reagent with DAPI (ThermoFisher Scientific).

\section{Cell counting}

The pyknotic cells as indicated by H\&E staining and the TUNEL-positive cells were counted in the subgranular zone (SGZ) of the dentate gyrus (DG). The 
numbers of BrdU- or Ki67-labeled cells as well as total number of Ibal positive and Iba1 positive with bushy morphology [31] in the short-term study or the numbers of BLBP-positive and PHH3-positive cells in the longterm study were counted in the SGZ. For the long-term study, BrdU-labelled cells were counted in the granular cell layer (GCL) using unbiased stereological counting techniques. For the immunofluorescent stainings, at least 50 BrdU-positive cells in the GCL were phenotyped using a confocal laser scanning microscope, and the ratio of BrdU-NeuN or BrdU-S100 $\beta$ double-labelled cells was calculated. The total number of newborn neurons or astrocytes in each sample was calculated based on the number of BrdU-positive cells and the ratio of double labelling.

\section{Creatinine measurement}

Blood samples were collected from the tail or when the animals were sacrificed. Serum was isolated by centrifugation and stored at $-80^{\circ} \mathrm{C}$. The concentration of creatinine in the serum was detected with serum creatinine kit (Cat. KBO2-H1, Arbor Assays).

\section{GCL volume evaluation}

The free-floating sections were stained with DAPI, and the area of the GCL in the DG was traced with a stereology system (Stereoinvestigator, MicroBrightField, Colchester, VT, USA). The volume was calculated by multiplying the sum of all areas by the section thickness $(30 \mu \mathrm{m})$ and the serial factor (12).

\section{Statistics}

All data were expressed as the mean \pm SEM. Student's $t$-test was used when comparing two groups. A two-way ANOVA was used when comparing the effects of lithium treatment and irradiation, and this was followed by a post-hoc test. Repeated measures ANOVA was used when comparing body weight gain, pituitary hormones, and behavioural tests. The significance level was set at $p<$ 0.05 . $\mathrm{IC}_{50}$ values were calculated from log-concentrationeffect curves in GraphPad Prism.

\section{CONFLICTS OF INTEREST} exists

The authors have declared that no conflict of interest

\section{GRANT SUPPORT}

This work was supported by the Swedish Research Council, the Swedish Childhood Cancer Foundation, the
Swedish Cancer Foundation, LUA/ALF governmental support for medical research, the Swedish Board of Radiation Safety, the Swedish Brain Foundation, the Gothenburg Medical Society, the Märta and Gunnar V. Philipson Foundation, the Swedish Society of Medicine, and the Deutsche Forschungsgemeinschaft (DFGFOR2107 to CC; DO 1525/3-1 to AD).

\section{REFERENCES}

1. Magnani C, Aareleid T, Viscomi S, Pastore G, Berrino F, Group EW, and EUROCARE Working Group. Variation in survival of children with central nervous system (CNS) malignancies diagnosed in Europe between 1978 and 1992: the EUROCARE study. Eur J Cancer. 2001; 37:711-21.

2. Mueller S, Chang S. Pediatric brain tumors: current treatment strategies and future therapeutic approaches. Neurotherapeutics. 2009; 6:570-86.

3. Padovani L, André N, Constine LS, Muracciole X. Neurocognitive function after radiotherapy for paediatric brain tumours. Nat Rev Neurol. 2012; 8:578-88.

4. Ellenberg L, Liu Q, Gioia G, Yasui Y, Packer RJ, Mertens A, Donaldson SS, Stovall M, Kadan-Lottick N, Armstrong G, Robison LL, Zeltzer LK. Neurocognitive status in long-term survivors of childhood CNS malignancies: a report from the Childhood Cancer Survivor Study. Neuropsychology. 2009; 23:705-17.

5. Liu R, Page M, Solheim K, Fox S, Chang SM. Quality of life in adults with brain tumors: current knowledge and future directions. Neuro-oncol. 2009; 11:330-39.

6. Blomstrand M, Brodin NP, Munck Af Rosenschöld P, Vogelius IR, Sánchez Merino G, Kiil-Berthlesen A, Blomgren K, Lannering B, Bentzen SM, Björk-Eriksson T. Estimated clinical benefit of protecting neurogenesis in the developing brain during radiation therapy for pediatric medulloblastoma. Neuro-oncol. 2012; 14:882-89.

7. Abayomi OK. Pathogenesis of irradiation-induced cognitive dysfunction. Acta Oncol. 1996; 35:659-63.

8. Monje M, Thomason ME, Rigolo L, Wang Y, Waber DP, Sallan SE, Golby AJ. Functional and structural differences in the hippocampus associated with memory deficits in adult survivors of acute lymphoblastic leukemia. Pediatr Blood Cancer. 2013; 60:293-300.

9. Huo K, Sun Y, Li H, Du X, Wang X, Karlsson N, Zhu C, Blomgren K. Lithium reduced neural progenitor apoptosis in the hippocampus and ameliorated functional deficits after irradiation to the immature mouse brain. Mol Cell Neurosci. 2012; 51:32-42.

10. Zhu C, Xu F, Fukuda A, Wang X, Fukuda H, Korhonen L, Hagberg H, Lannering B, Nilsson M, Eriksson PS, Northington FJ, Björk-Eriksson T, Lindholm D, Blomgren $\mathrm{K}$. X chromosome-linked inhibitor of apoptosis protein reduces oxidative stress after cerebral irradiation or hypoxia-ischemia through up-regulation of mitochondrial 
antioxidants. Eur J Neurosci. 2007; 26:3402-10.

11. Naylor AS, Bull C, Nilsson MK, Zhu C, Björk-Eriksson T, Eriksson PS, Blomgren K, Kuhn HG. Voluntary running rescues adult hippocampal neurogenesis after irradiation of the young mouse brain. Proc Natl Acad Sci USA. 2008; 105:14632-37.

12. Forbes ME, Paitsel M, Bourland JD, Riddle DR. Systemic effects of fractionated, whole-brain irradiation in young adult and aging rats. Radiat Res. 2013; 180:326-33.

13. Day J, Zienius K, Gehring K, Grosshans D, Taphoorn M, Grant R, Li J, Brown PD. Interventions for preventing and ameliorating cognitive deficits in adults treated with cranial irradiation. Cochrane Database Syst Rev. 2014CD011335.

14. Davis J, Ahlberg FM, Berk M, Ashley DM, Khasraw M. Emerging pharmacotherapy for cancer patients with cognitive dysfunction. BMC Neurol. 2013; 13:153.

15. Brown PD, Pugh S, Laack NN, Wefel JS, Khuntia D, Meyers C, Choucair A, Fox S, Suh JH, Roberge D, Kavadi V, Bentzen SM, Mehta MP, Watkins-Bruner D, and Radiation Therapy Oncology Group (RTOG). Memantine for the prevention of cognitive dysfunction in patients receiving whole-brain radiotherapy: a randomized, doubleblind, placebo-controlled trial. Neuro-oncol. 2013; 15:142937.

16. Wong P, Leppert IR, Roberge D, Boudam K, Brown PD, Muanza T, Pike GB, Chankowsky J, Mihalcioiu C. A pilot study using dynamic contrast enhanced-MRI as a response biomarker of the radioprotective effect of memantine in patients receiving whole brain radiotherapy. Oncotarget. 2016; 7: 50986-50996. doi: 10.18632/oncotarget.9653

17. Castellino SM, Ullrich NJ, Whelen MJ, Lange BJ. Developing interventions for cancer-related cognitive dysfunction in childhood cancer survivors. J Natl Cancer Inst. 2014; 106:106.

18. Erickson CA, Posey DJ, Stigler KA, Mullett J, Katschke AR, McDougle CJ. A retrospective study of memantine in children and adolescents with pervasive developmental disorders. Psychopharmacology (Berl). 2007; 191:141-47.

19. Sabel M, Sjölund A, Broeren J, Arvidsson D, Saury J-M, Gillenstrand J, Emanuelson I, Blomgren K, Lannering B. Effects of physically active video gaming on cognition and activities of daily living in childhood brain tumor survivors: a randomized pilot study. Neuro-Oncology Practice. 2016 doi: 10.1093/nop/npw020.

20. Sabel M, Sjölund A, Broeren J, Arvidsson D, Saury JM, Blomgren K, Lannering B, Emanuelson I. Active video gaming improves body coordination in survivors of childhood brain tumours. Disabil Rehabil. 2016; 38:207384.

21. Riggs L, Piscione J, Laughlin S, Cunningham T, Timmons BW, Courneya KS, Bartels U, Skocic J, de Medeiros C, Liu F, Persadie N, Scheinemann K, Scantlebury N, et al. Exercise training for neural recovery in a restricted sample of pediatric brain tumor survivors: a controlled clinical trial with crossover of training versus no training. Neurooncology. 2016. doi: 10.1093/neuonc/now177.

22. Khasraw M, Ashley D, Wheeler G, Berk M. Using lithium as a neuroprotective agent in patients with cancer. BMC Med. 2012; 10:131.

23. Yazlovitskaya EM, Edwards E, Thotala D, Fu A, Osusky KL, Whetsell WO Jr, Boone B, Shinohara ET, Hallahan DE. Lithium treatment prevents neurocognitive deficit resulting from cranial irradiation. Cancer Res. 2006; 66:11179-86.

24. Thotala DK, Geng L, Dickey AK, Hallahan DE, Yazlovitskaya EM. A new class of molecular targeted radioprotectors: GSK-3beta inhibitors. Int J Radiat Oncol Biol Phys. 2010; 76:557-65.

25. Malaterre J, McPherson CS, Denoyer D, Lai E, Hagekyriakou J, Lightowler S, Shudo K, Ernst M, Ashley DM, Short JL, Wheeler G, Ramsay RG. Enhanced lithiuminduced brain recovery following cranial irradiation is not impeded by inflammation. Stem Cells Transl Med. 2012; $1: 469-79$.

26. Li Q, Li H, Roughton K, Wang X, Kroemer G, Blomgren $\mathrm{K}$, Zhu C. Lithium reduces apoptosis and autophagy after neonatal hypoxia-ischemia. Cell Death Dis. 2010; 1:e56.

27. Contestabile A, Greco B, Ghezzi D, Tucci V, Benfenati F, Gasparini L. Lithium rescues synaptic plasticity and memory in Down syndrome mice. J Clin Invest. 2013; 123:348-61.

28. Zanni G, Di Martino E, Omelyanenko A, Andäng M, Delle U, Elmroth K, Blomgren K. Lithium increases proliferation of hippocampal neural stem/progenitor cells and rescues irradiation-induced cell cycle arrest in vitro. Oncotarget. 2015; 6:37083-97. doi: 10.18632/oncotarget.5191.

29. Zhukova N, Ramaswamy V, Remke M, Martin DC, Castelo-Branco P, Zhang CH, Fraser M, Tse K, Poon R, Shih DJ, Baskin B, Ray PN, Bouffet E, et al. WNT activation by lithium abrogates TP53 mutation associated radiation resistance in medulloblastoma. Acta Neuropathol Commun. 2014; 2:174.

30. Li H, Li Q, Du X, Sun Y, Wang X, Kroemer G, Blomgren $\mathrm{K}$, Zhu C. Lithium-mediated long-term neuroprotection in neonatal rat hypoxia-ischemia is associated with antiinflammatory effects and enhanced proliferation and survival of neural stem/progenitor cells. J Cereb Blood Flow Metab. 2011 May 18; 31:2106-15.

31. Xie C, Zhou K, Wang X, Blomgren K, Zhu C. Therapeutic benefits of delayed lithium administration in the neonatal rat after cerebral hypoxia-ischemia. PLoS One. 2014; 9:e107192.

32. Fukuda H, Fukuda A, Zhu C, Korhonen L, Swanpalmer J, Hertzman S, Leist M, Lannering B, Lindholm D, BjörkEriksson T, Marky I, Blomgren K. Irradiation-induced progenitor cell death in the developing brain is resistant to erythropoietin treatment and caspase inhibition. Cell Death Differ. 2004; 11:1166-78.

33. Smith MA, Makino S, Kim SY, Kvetnansky R. Stress 
increases brain-derived neurotropic factor messenger ribonucleic acid in the hypothalamus and pituitary. Endocrinology. 1995; 136:3743-50.

34. Zanni G, Michno W, Di Martino E, Tjärnlund-Wolf A, Pettersson J, Mason CE, Hellspong G, Blomgren K, Hanrieder J. Lithium Accumulates in Neurogenic Brain Regions as Revealed by High Resolution Ion Imaging. Sci Rep. 2017; 7:40726.

35. Cohen Y, Chetrit A, Cohen Y, Sirota P, Modan B. Cancer morbidity in psychiatric patients: influence of lithium carbonate treatment. Med Oncol. 1998; 15:32-36.

36. Martinsson L, Westman J, Hällgren J, Ösby U, Backlund L. Lithium treatment and cancer incidence in bipolar disorder. Bipolar Disord. 2016; 18:33-40.

37. Findling RL, Kafantaris V, Pavuluri M, McNamara NK, Frazier JA, Sikich L, Kowatch R, Rowles BM, Clemons TE, Taylor-Zapata P. Post-acute effectiveness of lithium in pediatric bipolar I disorder. J Child Adolesc Psychopharmacol. 2013; 23:80-90.

38. Baykara B, Inal-Emiroglu N, Karabay N, Cakmakci H, Cevher N, Senturk Pilan B, Alsen S. Increased hippocampal volumes in lithium treated adolescents with bipolar disorders: A structural MRI study. J Affect Disord. 2012;138:433-9.

39. Carret AS, Crevier L, Samson Y, Ellezam B, Décarie JC, Charpentier AM. Recurrent SHH/TP53-mutant medulloblastoma treated with a combination of lithium and radiotherapy. Abstracts from the 17th ISPNO meeting 2016.

40. Fukuda A, Fukuda H, Jönsson M, Swanpalmer J, Hertzman S, Lannering B, Björk-Eriksson T, Màrky I, Blomgren K. Progenitor cell injury after irradiation to the developing brain can be modulated by mild hypothermia or hyperthermia. J Neurochem. 2005; 94:1604-19.

41. Monje ML, Vogel H, Masek M, Ligon KL, Fisher PG, Palmer TD. Impaired human hippocampal neurogenesis after treatment for central nervous system malignancies. Ann Neurol. 2007; 62:515-20.

42. Moravan MJ, Olschowka JA, Williams JP, O'Banion MK. Cranial irradiation leads to acute and persistent neuroinflammation with delayed increases in T-cell infiltration and CD11c expression in C57BL/6 mouse brain. Radiat Res. 2011; 176:459-73.

43. Roughton K, Boström M, Kalm M, Blomgren K. Irradiation to the young mouse brain impaired white matter growth more in females than in males. Cell Death Dis. 2013; 4:e897.

44. Boström M, Kalm M, Karlsson N, Hellström Erkenstam N, Blomgren K. Irradiation to the young mouse brain caused long-term, progressive depletion of neurogenesis but did not disrupt the neurovascular niche. J Cereb Blood Flow Metab. 2013; 33:935-43.

45. Zhu C, Huang Z, Gao J, Zhang Y, Wang X, Karlsson N, Li Q, Lannering B, Björk-Eriksson T, Georg Kuhn H, Blomgren $\mathrm{K}$. Irradiation to the immature brain attenuates neurogenesis and exacerbates subsequent hypoxic-ischemic brain injury in the adult. J Neurochem. 2009; 111:1447-56.

46. Karlsson N, Kalm M, Nilsson MK, Mallard C, BjörkEriksson T, Blomgren K. Learning and activity after irradiation of the young mouse brain analyzed in adulthood using unbiased monitoring in a home cage environment. Radiat Res. 2011; 175:336-46.

47. Roughton K, Kalm M, Blomgren K. Sex-dependent differences in behavior and hippocampal neurogenesis after irradiation to the young mouse brain. Eur J Neurosci. 2012; 36:2763-72.

48. Kalm M, Fukuda A, Fukuda H, Ohrfelt A, Lannering B, Björk-Eriksson T, Blennow K, Márky I, Blomgren $\mathrm{K}$. Transient inflammation in neurogenic regions after irradiation of the developing brain. Radiat Res. 2009; 171:66-76.

49. Blomstrand $\mathrm{M}$, Kalm M, Grandér R, Björk-Eriksson $\mathrm{T}$, Blomgren K. Different reactions to irradiation in the juvenile and adult hippocampus. Int J Radiat Biol. 2014; 90:807-15.

50. Monje ML, Mizumatsu S, Fike JR, Palmer TD. Irradiation induces neural precursor-cell dysfunction. Nat Med. 2002; 8:955-62.

51. Monje ML, Toda H, Palmer TD. Inflammatory blockade restores adult hippocampal neurogenesis. Science. 2003; 302:1760-65.

52. Correa F, Mallard C, Nilsson M, Sandberg M. Activated microglia decrease histone acetylation and Nrf2-inducible anti-oxidant defence in astrocytes: restoring effects of inhibitors of HDACs, p38 MAPK and GSK3 $\beta$. Neurobiol Dis. 2011; 44:142-51.

53. Duffner PK. Long-term effects of radiation therapy on cognitive and endocrine function in children with leukemia and brain tumors. Neurologist. 2004; 10:293-310.

54. Schmiegelow M, Lassen S, Poulsen HS, Feldt-Rasmussen U, Schmiegelow K, Hertz H, Müller J. Cranial radiotherapy of childhood brain tumours: growth hormone deficiency and its relation to the biological effective dose of irradiation in a large population based study. Clin Endocrinol (Oxf). 2000; 53:191-97.

55. Schmiegelow M, Feldt-Rasmussen U, Rasmussen AK, Poulsen HS, Müller J. A population-based study of thyroid function after radiotherapy and chemotherapy for a childhood brain tumor. J Clin Endocrinol Metab. 2003; 88:136-40.

56. Wickström M, Dyberg C, Milosevic J, Einvik C, Calero R, Sveinbjörnsson B, Sandén E, Darabi A, Siesjö P, Kool M, Kogner P, Baryawno N, Johnsen JI. Wnt/ $\beta$-catenin pathway regulates MGMT gene expression in cancer and inhibition of Wnt signalling prevents chemoresistance. Nat Commun. 2015; 6:8904.

57. Dolga AM, Letsche T, Gold M, Doti N, Bacher M, Chiamvimonvat N, Dodel R, Culmsee C. Activation of $\mathrm{KCNN} 3 / \mathrm{SK} 3 / \mathrm{K}(\mathrm{Ca}) 2.3$ channels attenuates enhanced 
calcium influx and inflammatory cytokine production in activated microglia. Glia. 2012; 60:2050-64.

58. Fukuda A, Fukuda H, Swanpalmer J, Hertzman S, Lannering B, Marky I, Björk-Eriksson T, Blomgren K. Age-dependent sensitivity of the developing brain to irradiation is correlated with the number and vulnerability of progenitor cells. J Neurochem. 2005; 92:569-84.

59. Fowler JF. The linear-quadratic formula and progress in fractionated radiotherapy. Br J Radiol. 1989; 62:679-94.
60. Zhu C, Gao J, Karlsson N, Li Q, Zhang Y, Huang Z, Li $\mathrm{H}$, Kuhn HG, Blomgren K. Isoflurane anesthesia induced persistent, progressive memory impairment, caused a loss of neural stem cells, and reduced neurogenesis in young, but not adult, rodents. J Cereb Blood Flow Metab. 2010; 30:1017-30. 